\title{
VERTICAL LIFTING ICE FORCES CAUSED BY A RISING WATER LEVEL, AND THEIR ACTION ON A VERTICAL SLENDER STRUCTURE (PILE)
}

\author{
(Abstract only)
}

\author{
by \\ Per Tryde \\ (Institute of Hydrodynamics and Hydraulic Engineering, Technical University of Denmark, \\ DK-2800 Lyngby, Denmark)
}

ABSTRACT

The problem of vertical lifting ice forces caused by a rising water level, and their action on a vertical slender structure (pile), has been studied by use of the classical theory of an elastic plate resting on an elastic support, in order to calculate the moments and normal forces in the sheet that cause rupture and thus produce cracks in the sheet (Nevel 1974). When cracks are formed, the continuous rise of the water level tends to widen them further, and the theory of elasticity is no longer valid. Usually, formation of cracks in structural members results in complete failure, but this may not be the case here. If the temperature of the air is below zero, the water penetrating the cracks will freeze when it meets with the upper part of the ice and with the air, both having a temperature far below the freezing point of water. Thus the cracks will be continuously healed up, as they are widened by the rising water level. A material healing its own cracks along the rupture zone gives a completely changed stress/strain situation during the deformation.

This new approach may lead to a theory which is able to predict the uplift forces of ice as a function of time, of frequency and amplitude of waterlevel fluctuations, and of air temperature. It appears that the pile is lifted only a short distance with each cycle of water-level fluctuation. Since the downward ice force is smaller than the upward force, and the pile has a larger resistance to compression than to pulling, the pile may eventually, in the course of repeated cycles, be lifted several inetres.

REFERENCE

Nevel D 1974 The ultimate failure of a floating ice sheet. In IAHR. International Association for Hydraulic Research. Symposium on ice and its action on hydraulic structures, Leningrad, 1972 [Vol 2]: $17-22$ 